\title{
Seasonal change in sexual differences in nestling size and survival: a framework to evaluate sex-dependent environmental sensitivity in the wild
}

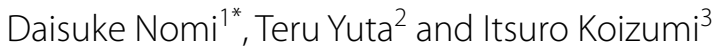

\begin{abstract}
Background: Sexual size dimorphism (SSD) occurs in a wide range of species in birds and other animals, but the magnitude of SSD often varies with environmental conditions. In general, in the developmental stages, the larger sex is more vulnerable to adverse environmental conditions because the larger sex requires more energy than the smaller sex. However, this may not hold true for birds with large brood sizes; the larger sex can acquire more food by suppressing the smaller sex. In addition, most previous studies have been experimental, such as by manipulating clutch size and ectoparasites, which may not reflect natural conditions.
\end{abstract}

Methods: In the present study, we propose a general framework to assess sexual differences in environmental sensitivity in natural populations. Because environmental conditions change throughout the breeding season, seasonal changes of nestling SSD and sex ratio should reflect sexual differences in environmental sensitivity. We applied this approach to a large dataset (1555 nestlings over 5 years) of Japanese Tits (Parus minor). In this population, the male nestling is generally larger than the female (5\% SSD in body weight).

Results: We found that the magnitude of SSD (weight, tarsus, wing) and fledgling sex ratio increased both in the beginning and the end of the breeding season.

Conclusion: Our study suggested that female nestlings are more valuable to poor environmental conditions in the relatively fecund species. This study underscores the importance of brood size on sexual differences in environmental stochasticity and our framework encourages comparative analysis among different bird species.

Keywords: Brood size, Japanese tit, Parus minor, Seasonal change, Sexual size dimorphism

\section{Background}

Environmental conditions during early developmental stages can have long-term effects on individual life history (Lindström 1999; Monaghan 2008). For sexually dimorphic species, neonatal conditions are especially important because either one of the sexes could be more significantly influenced by environmental stochasticity. For example, female nestlings in raptors and

\footnotetext{
*Correspondence: Daisuke.Nomi@ees.hokudai.ac.jp

${ }^{1}$ Graduate School of Environmental Science, Hokkaido University, Sapporo, Hokkaido, Japan

Full list of author information is available at the end of the article
}

male juveniles in mammals, the larger sexes, tend to be strongly influenced by poor environmental conditions due to their higher energy requirement (costly sex hypothesis, Clutton-Brock et al. 1985; Teather and Weatherhead 1989; Kalmbach and Benito 2007; Jones et al. 2009). Conversely, the larger sex will experience greater fitness benefits under favorable conditions (Jones et al. 2009). Therefore, sexual differences in environmental sensitivity can significantly affect individual fitness and even allocation of offspring sex ratio (Trivers and Willard 1973).

The costly sex hypothesis has been widely supported for species with small litter/brood sizes and large 
sexual size dimorphism (SSD) (Clutton-Brock et al. 1985; Teather and Weatherhead 1989; Kalmbach and Benito 2007; Jones et al. 2009). However, some recent studies of birds with large brood sizes and small SSD suggested that the smaller sex is more sensitive to poor conditions (Oddie 2000; Potti et al. 2002; Råberg et al. 2005; Dubiec et al. 2006; Nicolaus et al. 2009), although other studies have shown the opposite pattern (Tschirren et al. 2003; Chin et al. 2005; Dietrich-Bischoff et al. 2008). In the case of strong sibling competition for food delivered by parents, a larger body size may be advantageous (competitive advantage hypothesis, Nilsson and Gårdmark 2001; Nicolaus et al. 2009). Therefore, the mixed results among previous studies necessitate further research on species with large brood sizes. Moreover, most previous studies on birds with a large brood size and small SSD have been conducted experimentally, such as by adding/removing nestling to clutches or ectoparasites (Råberg et al. 2005; Kalmbach and Benito 2007), which may not reflect natural conditions. Thus, more observational studies are needed to confirm patterns under natural conditions.

We propose a general framework to assess the sexual differences in environmental sensitivity under natural conditions by monitoring seasonal change in the magnitude of SSD and fledging sex ratio (Fig. 1). First, seasonal change in nestling growth should be curvilinear (peak in mid-season) rather than a simple increasing or decreasing trend because in general, some pairs in a population start breeding early or late from the peak of food availability (i.e. abundance and/or quality of prey item, Naef-Daenzer and Keller 1999; Verboven et al. 2001; García-Navas and Sanz 2011). Therefore, if male and female nestlings respond differently to the environment, seasonal change in SSD should reflect this environmental vulnerability (Fig. 1a, b). When males are larger, and if males are more sensitive, the magnitude of SSD would be smaller both in the beginning and end of the breeding season (Fig. 1a). Conversely, if females are more sensitive, the magnitude of SSD would be larger both at the beginning and the end of the breeding season (Fig. 1b). A similar prediction applies to sexual differences in nestling mortality. If males are more sensitive, the proportion of males at fledging would be lower both at the beginning and the end of the breeding season (Fig. 1c). Alternatively, if females are more sensitive, the proportion of males would be higher both at the beginning and the end of the breeding season (Fig. 1d). In this study, we applied this approach to a large data set (1555 nestlings over 5 years) of Japanese Tits (Parus minor) in a temperate forest in northern Japan.

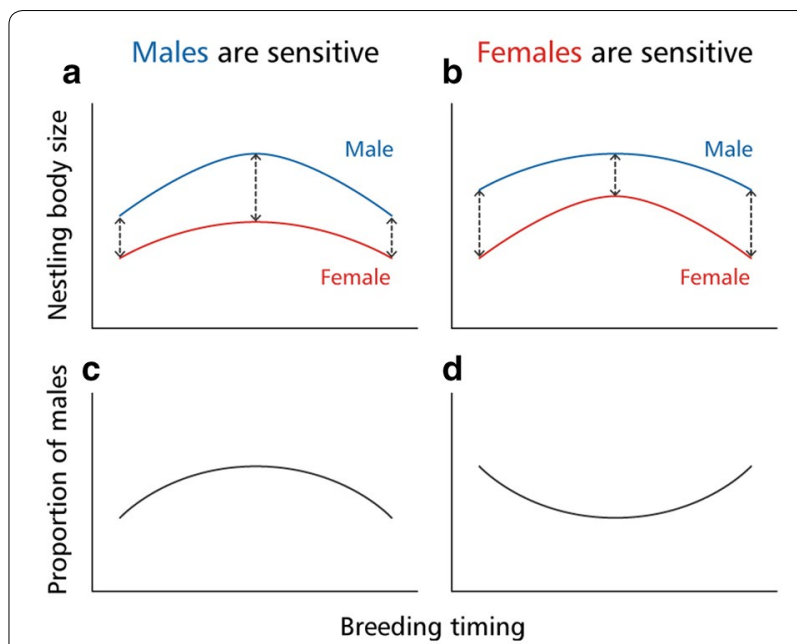

Fig. 1 Conceptual models of seasonal change of male and female nestling body size and fledgling sex ratio when males are more sensitive $(\mathbf{a}, \mathbf{c})$ and females are more sensitive $(\mathbf{b}, \mathbf{d})$. Dashed arrows show the difference between the male and female body size

\section{Methods}

\section{Study species, study sites, and field procedures}

The Japanese Tit is a small (ca. 14 g) hole-nesting passerine that readily accepts nest boxes for breeding. This species is sexually dimorphic and sex differences appear in the nestling period (5\% of male biased SSD in body weight; Nomi et al. 2015). In our study area, the Japanese Tit has a large brood size in the first and later clutches. However, clutch size and fledging success were lower in later clutches (10.2 for the first, range $7-13$, and 8.2 for the second clutches, range 5-10; Nomi et al. 2015), most likely because food quality and abundance were unfavorable later in the season (Murakami 2002).

Fieldwork was conducted over 5 years (2009-2010, 2012-2014) in the Tomakomai Experimental Forest $\left(42.40^{\circ} \mathrm{N}, 141.36^{\circ} \mathrm{E}, 5-90 \mathrm{~m}\right.$ a.s.l.), Hokkaido, northern Japan. The study area belongs to the cool temperate climate zone and is covered with mixed deciduous forests. We established two study sites in the forest (ca. 30 ha each) in 2008 with approximately 150 nest boxes at each site (Yuta and Koizumi 2012; Nomi et al. 2015). During the breeding season (late April to late August), we checked all the nest boxes weekly and recorded basic information, such as laying date and clutch size. Hatching date and fledging date of broods were confirmed by daily observation (date of one or more nestlings hatched or fledged). Parents were caught and ringed for individual identification when nestlings were 5-7 days old and measured at the same time. Body weight was measured using an electronic balance (accuracy: $0.1 \mathrm{~g}$ ). Tarsus length was measured using a digital caliper to the nearest $0.01 \mathrm{~mm}$. Wing length was measured using a ruler to the 
nearest $0.5 \mathrm{~mm}$. Nestlings were caught and measured on day $10-15$ post-hatching. After measuring, blood samples $(10-50 \mu \mathrm{L})$ from the brachial vein were collected and stored in $99 \%$ ethanol for molecular sexing.

\section{Sex determination}

Sex determination was conducted following the protocol in Nomi et al. (2015). After extracting DNA from samples, we used the primers P8 and P2 to amplify sex specific regions of the CHD gene, which is often used for sex determination in birds (Griffiths et al. 1998). Birds were sexed according to the presence of the PCR products of CHD-Z (both sexes) and CHD-W (females only), which were separated by electrophoresis. We confirmed the accuracy of molecular sexing using the parents' samples with known sexes.

\section{Statistical analyses}

\section{Seasonal change in the magnitude of SSD}

For the analysis of seasonal change in the magnitude of SSD, we used linear mixed models (LMM). The response variable was body weight, tarsus length, or wing length of nestlings. The explanatory variables in the full model included hatching date, square of hatching date, sex, interaction between the hatching date and sex, and interaction between the square of hatching date and sex as main effects. We included nest ID, study site, and year as random effects. Number of nestlings (brood size when nestlings were caught), nestling age, and maternal traits (weight, tarsus length, and wing length in each analysis) were also included as covariates. We did not include paternal traits because some nestlings were sired by extra-pair males in this population and their genetic fathers were not identified (Yuta and Koizumi 2016). Since the mean timing and length of the breeding season varied among years, we standardized the hatching date of each nest by compressing the hatching date to a range from 0 to 1 (standardized hatching date $=$ (hatching date - earliest hatching date)/hatching date range). Standardized hatching date (hereafter termed hatching date) and sex were centered by subtracting the mean prior to the analyses to avoid multicollinearity between the variables and interactions (Robinson and Schumacker 2009).

To examine the seasonal change of the magnitude of SSD, seasonal change of male and female nestling body traits estimated by the best models were assigned to the Storer's index of the magnitude of SSD (difference between the values of male and female body traits divided by the mean values of male and female traits, Benito and Gonzalez-Solis 2007).

\section{Seasonal change in fledgling sex ratio}

We defined the fledgling sex ratio as the proportion of male nestlings on the capturing dates (10-15 days old) because almost all nestlings successfully fledged if they were alive on the capturing dates. However, if dead nestlings were found after the capturing date, they were excluded from the analysis. We constructed generalized linear mixed models (GLMM) with a logit-link function with a binomial error distribution for the analysis. The response variable was nestling sex (male: 1 , female: 0 ), and the explanatory variables were hatching date, square of hatching date, and brood size. Random effects included nest ID, female ID, site, and year. We excluded depredated nests from the analysis because nest predation potentially biases the fledgling sex ratio. To confirm that the fledgling sex ratio was independent of sex allocation at the time of laying (primary sex ratio), we conducted the same analysis using the data of nests in which the number of eggs and fledglings were equal.

We performed all the analyses using the statistical software R 2.15.3 (R Development Core Team 2013) with package "lme4" for LMMs and GLMMs. Multicollinearity of explanatory variables was tested using the variance inflation factor (VIF) with the package "car". The VIF of all variables was under 3.5 after centering and were under the threshold value of 5.0 recommended by O'Brien (2007). To confirm whether curvilinear models were better than simple linear models, and whether the models with an interaction between hatching date and sex were better than the models without interaction, we compared all candidate models (i.e. different combinations of the explanatory variables) using AIC (Burnham and Anderson 2002). The model with the lowest AIC value in each analysis was determined to be the best model. The significance of the partial coefficient of each variable in the best model was examined by the likelihood ratio test comparing the models with and without the terms of interest.

\section{Results}

Seasonal change in the magnitude of SSD

In the 5 years of this study, we collected data on 1555 nestlings from 194 broods. We examined seasonal change in the magnitude of SSD in three nestling body traits (body weight, tarsus length, and wing length). We compared models with linear hatching date effects and the quadratic term of the hatching date, as well as the models with and without their interactions with sex, using AIC. In all three analyses, the models with the square of hatching date and the interaction of the square of hatching date and sex had the lowest AIC values (Table 1, Additional file 1: Table S1, Additional file 2: Table S2, Additional file 3: Table S3), meaning that the sex specific curvilinear model was the best model for predicting seasonal 
Table 1 Model ranking of the GLMMs according to the AIC

\begin{tabular}{|c|c|c|}
\hline Response & Model & AIC \\
\hline \multirow[t]{4}{*}{ Nestling body weight } & $\begin{array}{l}\text { Hatching date^ } 2+\text { sex }+ \text { hatching } \\
\text { date^ } 2^{*} \text { sex }\end{array}$ & 3657.2 \\
\hline & Hatching date^ $2+$ sex & 3668.2 \\
\hline & $\begin{array}{l}\text { Hatching date }+ \text { sex }+ \text { hatching } \\
\text { date }{ }^{*} \text { sex }\end{array}$ & 3691.5 \\
\hline & Hatching date + sex & 3694.8 \\
\hline \multirow[t]{4}{*}{ Nestling tarsus length } & $\begin{array}{l}\text { Hatching date^ } 2+\text { sex }+ \text { hatching } \\
\text { date^ } 2 * \operatorname{sex}\end{array}$ & 2691.5 \\
\hline & Hatching date $\wedge 2+$ sex & 2698.0 \\
\hline & $\begin{array}{l}\text { Hatching date }+ \text { sex }+ \text { hatching } \\
\text { date * }{ }^{*} \text { sex }\end{array}$ & 2709.8 \\
\hline & Hatching date + sex & 2711.4 \\
\hline \multirow[t]{4}{*}{ Nestling wing length } & $\begin{array}{l}\text { Hatching date^ } 2+\text { sex }+ \text { hatching } \\
\text { date^ } 2 * \text { sex }\end{array}$ & 7727.4 \\
\hline & Hatching date^ $2+\operatorname{sex}$ & 7739.2 \\
\hline & $\begin{array}{l}\text { Hatching date }+ \text { sex }+ \text { hatching } \\
\text { date }{ }^{*} \text { sex }\end{array}$ & 7741.9 \\
\hline & Hatching date + sex & 7742.0 \\
\hline \multirow[t]{5}{*}{ Fledgling sex ratio } & Hatching date $\wedge 2+$ hatching date & 2074.5 \\
\hline & Hatching date^2 & 2074.8 \\
\hline & Hatching date $\wedge 2+$ brood size & 2075.5 \\
\hline & $\begin{array}{l}\text { Hatching date } \wedge 2+\text { hatching } \\
\text { date }+ \text { brood size }\end{array}$ & 2076.4 \\
\hline & Null & 2076.6 \\
\hline
\end{tabular}

Curvilinear models (including the square of hatching date or/and interaction with sex) and linear models (hatching date or/and interaction with sex) with the lowest AIC value are shown in the table. Covariates in the models are not shown in the body size analyses in this table. All models are shown in Additional file 1: Table S1, Additional file 2: Table S2, Additional file 3: Table S3, Additional file 4: Table S4

change in nestling body size. For body weight and tarsus length, the square of hatching date, sex, and the interaction between the square of hatching date and sex were all significant (Table 2). For wing length, although the square of hatching date was not significant, interaction between the square of hatching date and sex was significantly correlated, indicating that seasonal change in growth of wing length was sex specific. In all nestling body traits, the magnitude of SSD was higher both at the beginning and the end of the breeding season (Fig. 2).

\section{Seasonal change in fledgling sex ratio}

We also examined seasonal change in fledgling sex ratio to elucidate which sex was more vulnerable in poor environmental conditions. Comparisons of models by AIC showed that the curvilinear model was better than the single linear model (Table 1, Additional file 4: Table S4). In the analysis, the square of hatching date was significant (Table 2). The proportion of males was higher both in the beginning and end of the breeding season (Fig. 3). To examine whether the seasonal change in proportion of males was a result of primary sex allocation (sex ratio at eggs), we conducted the same analysis using nests with no loss of nestlings (the number of fledglings was equal to the number of eggs). Primary sex ratio (proportion of males in eggs) did not have a significant curvilinear relationship with hatching date $(n=936$, partial coefficient of the square of hatching date; $x^{2}=2.82, p=0.09$ ), indicating that the seasonal change in fledgling sex ratio was not the result of primary sex allocation of female parents, but rather the result of female-biased mortality.

\section{Discussion}

Our results consistently suggested that female Japanese Tit nestlings are more vulnerable to adverse environments. This agrees with most experimental studies on species with large brood sizes (Oddie 2000; Potti et al. 2002; Råberg et al. 2005; Dubiec et al. 2006; Nicolaus et al. 2009, but see Tschirren et al. 2003; Chin et al. 2005) and a few observational studies (Dhondt 1970; Eeva et al. 2012, but see Dietrich-Bischoff et al. 2008). Our approach was observational and, therefore, a clear demonstration of the causal link was not possible. In fact, the increase of SSD in the end of the breeding season can also be explained by factors other than poor environmental conditions. For example, multiple brooding is energy-consuming for parents, which could result in poorer parental body conditions, and consequently food delivery rate might have reduced. However, the main question in this topic is which sex is more valuable when the parental provisioning is not sufficient: for nestlings, parental condition and behavior can also be considered as environmental factors. Poor external environmental conditions and poor parental conditions should similarly affect the nestlings. In addition, past experimental studies have not controlled the external environment either; these studies examined the sexual differences of environmental stochasticity by changing the food intake per nestling by adding or removing clutches (Råberg et al. 2005; Dubiec et al. 2006; Nicolaus et al. 2009). In this sense, we need not change the main conclusion that female nestlings are more valuable under poor environmental condition.

On the other hand, observational study has some advantages. For example, while many experimental studies were conducted under extreme conditions, our approach and results reflect natural settings. Moreover, seasonal changes in nestling or fledgling characteristics are commonly monitored; thus, this approach can easily apply to many study systems, which in turn encourages comparative studies or meta-analysis. Based on past studies, it seems that male nestlings are more sensitive in species with small brood sizes, whereas the opposite is true in species with large brood sizes (Jones et al. 2009).

As suggested by Råberg et al. (2005), parents of large broods might not able to control distributing food and 
Table 2 Parameter estimates and $p$ values of the best models of GLMMs

\begin{tabular}{|c|c|c|c|c|c|}
\hline Parameter & Estimate & SE & df & $x^{2}$ & $p$ \\
\hline Nestling body weight & $n=1555$ & & & & \\
\hline Intercept & 11.775 & 0.869 & 1 & 17.01 & $<0.001$ \\
\hline Hatching date & 0.909 & 0.181 & 1 & 24.07 & $<0.001$ \\
\hline Hatching date^^2 & -3.088 & 0.598 & 1 & 25.40 & $<0.001$ \\
\hline Sex & 0.550 & 0.052 & 1 & 108.90 & $<0.001$ \\
\hline Hatching date $\wedge 2 *$ sex & 1.871 & 0.458 & 1 & 16.59 & $<0.001$ \\
\hline Female body weight & 0.194 & 0.059 & 1 & 10.83 & $<0.001$ \\
\hline Nestling tarsus length & $n=1555$ & & & & \\
\hline Intercept & 11.497 & 1.032 & 1 & 24.83 & $<0.001$ \\
\hline Hatching date $\wedge 2$ & -1.222 & 0.293 & 1 & 17.09 & $<0.001$ \\
\hline Sex & 0.441 & 0.039 & 1 & 125.54 & $<0.001$ \\
\hline Hatching date $\wedge 2 *$ sex & 1.009 & 0.339 & 1 & 8.85 & 0.003 \\
\hline Age & 0.204 & 0.040 & 1 & 25.60 & $<0.001$ \\
\hline Female tarsus length & 0.311 & 0.045 & 1 & 43.02 & $<0.001$ \\
\hline Nestling wing length & $n=1545$ & & & & \\
\hline Intercept & 0.167 & 3.676 & 1 & $<0.01$ & 0.947 \\
\hline Hatching date $\wedge 2$ & -3.074 & 2.051 & 1 & 2.31 & 0.129 \\
\hline Sex & 0.393 & 0.195 & 1 & 4.07 & 0.044 \\
\hline Hatching date $\wedge 2 *$ sex & 5.715 & 1.732 & 1 & 10.85 & $<0.001$ \\
\hline Age & 2.994 & 0.271 & 1 & 91.97 & $<0.001$ \\
\hline Brood size & 0.288 & 0.102 & 1 & 7.93 & 0.005 \\
\hline $\begin{array}{l}\text { Fledgling sex ratio }(1=\text { male } \\
0=\text { female) }\end{array}$ & $n=1491$ & & & & \\
\hline Intercept & -0.124 & 0.082 & 1 & 2.32 & 0.128 \\
\hline Hatching date^2 & 1.901 & 0.775 & 1 & 6.08 & 0.014 \\
\hline Hatching date & -0.337 & 0.224 & 1 & 2.28 & 0.132 \\
\hline
\end{tabular}

Chi squared value and $p$ values were obtained from likelihood ratio tests

the larger sex has an advantage in sibling competition. For example, in Great Tits, the feeding position of individual parents is consistent through the breeding period (Poelman et al. 2006). Therefore, the larger nestlings could monopolize food delivered by the parents by moving toward the best position. Moreover, most species with large brood size, like Japanese Tits or Great Tits, are cavity nesters and therefore, it may be difficult for parents to distinguish between hungry and full nestlings in dark environment.

Alternatively, it is also possible that parents favored larger nestlings in poor condition and delivered more food to the larger nestlings (Jones et al. 2009; Caro et al. 2016). To disentangle whether it is a result of parental favoritism to larger nestling or of sibling competition, more observations are needed inside the nest boxes comparing good and poor environmental condition.

In addition to this study's main results, we found patterns in the magnitude of SSD. First, the SSD of nestling body traits were larger at the end of the breeding season than in the beginning (Fig. 2). This may be because food abundance in this study site is lower in the end of the breeding season than in the beginning. Although caterpillar abundance and diversity in the studied forest had two peaks in the season (Yoshida 1985), clutch size and fledging success was lower in the later clutches (Yuta and Koizumi 2012), indicating that environmental condition including food availability were less favorable towards the end of the breeding season. Moreover, asynchronous hatching timing in a brood might also have increased sex difference later in the season. Hatching asynchrony, which is considered as a maternal adjustment under poor food availability, becomes more prominent later in the season (Theofanellis et al. 2008) and more severely affects the growth of late-hatched female nestling compared to male siblings (Oddie 2000). Some nestlings might have hatched 1-3 days later than the first hatched nestling in a brood, but we did not confirm hatching dates of all nestlings. Thus, larger SSD later in the breeding season may be the result of increased hatching asynchrony as well as decreased food availability.

Second, we found that the SSD of nestlings was smaller for tarsus length and wing length compared with body weight. This may be the result of differences in growth speed among body traits. For example, the tarsus grows faster than body weight or wing length and reaches a maximum around 10 days old (Royama 1966). In terms of wing length, sex differences in growth strategies have been reported in many studies (Oddie 2000; Råberg et al. 2005; Dubiec et al. 2006; Nicolaus et al. 2009). Since the female is the more dispersing sex, they may invest more in wing length than in body weight under poor conditions (Greenwood 1980). Therefore, while significant differences were detected in the Japanese Tit, the sexual difference was subtle in wing length. In contrast, males may allocate more into body weight because body weight plays an important role in competition among individuals and, thus, in the process of territory acquisition (Garnett 1981; Sandell and Smith 1991).

As discussed in some recent studies, differential effects of adverse condition on male and female traits may be a result of allocation of resources rather than the difference in sensitivity between the sexes (Tschirren et al. 2003). Similar to wing length, selective pressure may work differently on body traits between the sexes and future studies should focus more on this point.

\section{Conclusion}

Our study showed that female Japanese Tit nestlings are more valuable to poor environmental conditions, which is consistent with most experimental studies on species with large brood sizes. However, whether it is a result 

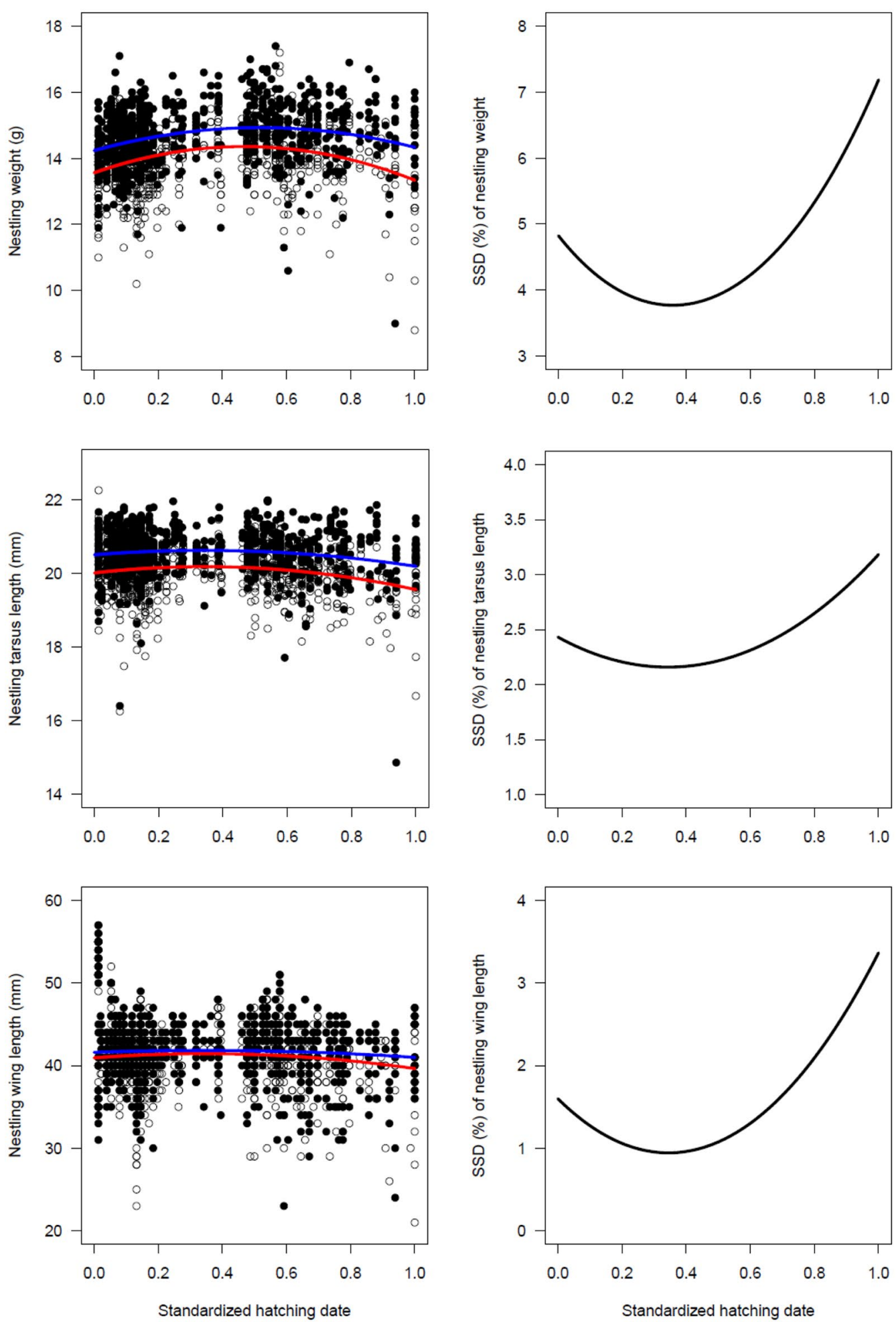

Fig. 2 The relationship between hatching date and nestling body traits (left figures) and the magnitude of SSD (right figures). Parameters were estimated using the linear mixed model shown in Table 2. Lines are predicted values (male: blue, female: red). Filled circles represent males and open circles represent females. Seasonal changes of the magnitude of SSD were calculated using the best models shown in Table 2, where predicted lines of male and female body size were assigned to the Storer's index of the magnitude of SSD (difference between the values of male and female body size divided by the mean values of male and female size, Benito and Gonzalez-Solis 2007) 


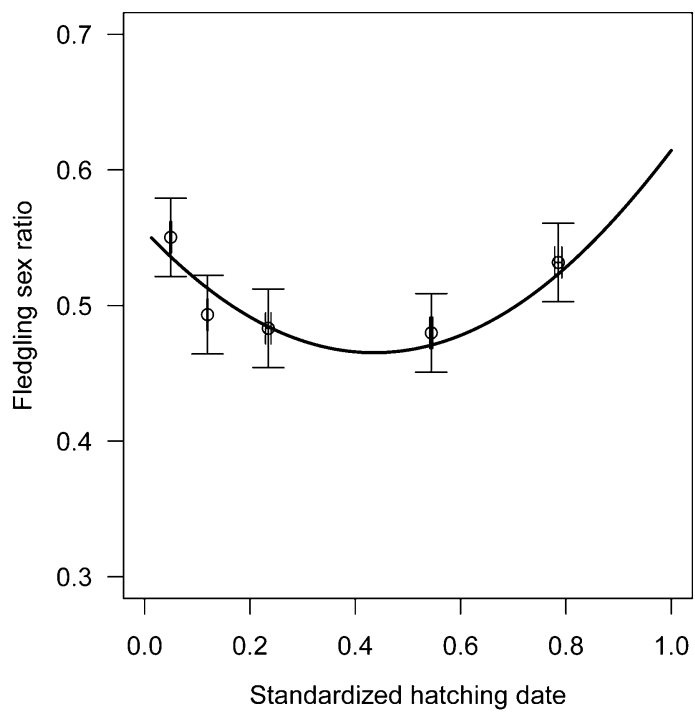

Fig. 3 The relationship between hatching date and fledgling sex ratio (proportion of males). Plots and bars represent mean values and standard errors, which are calculated by dividing the data into 5 rank categories starting from the lowest value of standardized hatching date (first 4 plots, 298 samples; last plot, 299 samples). Parameters were estimated using the generalized linear mixed model shown in Table 2 . The line is the predicted value

of parental favoritism to larger nestling or of sibling competition is still unclear. Our study underscores the importance of brood size on sexual differences in environmental stochasticity and our framework encourages comparative analysis among different bird species.

\section{Additional files}

Additional file 1: Table S1. Model ranking of the LMM for nestling weight according to the AIC.

Additional file 2: Table S2. Model ranking of the LMM for nestling tarsus length according to the AIC.

Additional file 3: Table S3. Model ranking of the LMM for nestling wing length according to the AIC.

Additional file 4: Table S4. Model ranking of the GLMM for fledgling sex ratio according to the AIC.

\section{Authors' contributions}

DN and TY collected the data; DN analysed the data; DN and IK wrote the paper. All authors read and approved the final manuscript.

\section{Author details}

${ }^{1}$ Graduate School of Environmental Science, Hokkaido University, Sapporo, Hokkaido, Japan. ${ }^{2}$ Center for Toki and Ecological Restoration, Niigata University, Sado, Niigata, Japan. ${ }^{3}$ Faculty of Environmental Earth Science, Hokkaido University, Sapporo, Hokkaido, Japan.

\section{Acknowledgements}

We acknowledge the valuable comments of an anonymous reviewer on earlier version of the manuscript. We thank researchers and staff of the
Tomakomai Experimental Forest for field work assistance and for their hospitality while we stayed there. We also thank laboratory members for field work assistance, and C. G. Ayer for helping to improve our use of English.

\section{Competing interests}

The authors declare that they have no conflict of interests.

\section{Availability of data and materials}

The datasets used in the present study are available from the corresponding author on reasonable request.

\section{Consent for publication}

Not applicable.

\section{Ethics approval}

Capture permissions were obtained every year from the Hokkaido Government Iburi General Subprefectural Bureau (License Number: 78, 91, 31, $283-284,277-278,252-253)$

\section{Funding}

Out study received no funding support.

Received: 23 September 2017 Accepted: 8 March 2018

Published online: 19 March 2018

\section{References}

Benito MM, Gonzalez-Solis J. Sex ratio, sex-specific chick mortality and sexual size dimorphism in birds. J Evol Biol. 2007;20:1522-30.

Burnham KP, Anderson DR. Model selection and multimodel inference: a practical information-theoretic approach. Berlin: Springer; 2002.

Caro SM, Griffin AS, Hinde CA, West SA. Unpredictable environments lead to the evolution of parental neglect in birds. Nat Commun. 2016;7:10985.

Chin EH, Love OP, Clark AM, Williams TD. Brood size and environmental conditions sex-specifically affect nestling immune response in the European starling Sturnus vulgaris. J Avian Biol. 2005;36:549-54.

Clutton-BrockTH, Albon SD, Guinness FE. Parental investment and sex differences in juvenile mortality in birds and mammals. Nature. 1985;313:131-3.

Dietrich-Bischoff V, Schmoll T, Winkel W, Lubjuhn T. Variation in the magnitude of sexual size dimorphism in nestling Coal tits (Periparus ater). J Ornithol. 2008;149:565-77.

Dhondt AA. The sex ratio of nestling great tits. Bird Study. 1970;17:282-6.

Dubiec A, Cichoń M, Deptuch K. Sex-specific development of cell-mediated immunity under experimentally altered rearing conditions in blue tit nestlings. Proc R Soc Lond B. 2006;273:1759-64.

Eeva T, Sillanpää S, Lehikoinen E. Metal pollution does not bias offspring sex ratio in great tit (Parus major). Environ Sci Pollut Res. 2012;19:2870-8.

García-Navas V, Sanz JJ. The importance of a main dish: nestling diet and foraging behaviour in Mediterranean blue tits in relation to prey phenology. Oecologia. 2011;165:639-49.

Garnett MC. Body size, its heritability and influence on juvenile survival among Great Tits Parus major. Ibis. 1981;123:31-41.

Greenwood PJ. Mating systems, philopatry and dispersal in birds and mammals. Anim Behav. 1980;28:1140-62.

Griffiths R, Double MC, Orr K, Dawson RJG. A DNA test to sex most birds. Mol Ecol. 1998;7:1071-5.

Jones KS, Nakagawa S, Sheldon BC. Environmental sensitivity in relation to size and sex in birds: meta-regression analysis. Am Nat. 2009;174:122-33.

Kalmbach E, Benito MM. Sexual size dimorphism and offspring vulnerability in birds. In: Fairbairn DJ, Blanckenhorn WU, Szekely T, editors. Sex, size and gender roles: evolutionary studies of sexual size dimorphism. Oxford: Oxford University Press; 2007. p. 133-42.

Lindström J. Early development and fitness in birds and mammals. Trends Ecol Evol. 1999;14:343-8.

Murakami M. Foraging mode shifts of four insectivorous bird species under temporally varying resource distribution in a Japanese deciduous forest. Ornithol Sci. 2002;1:63-9. 
Monaghan P. Early growth conditions, phenotypic development and environmental change. Philos Trans R Soc Lond B. 2008;363:1635-45.

Naef-Daenzer B, Keller LF. The foraging performance of great and blue tits (Parus major and P. caeruleus) in relation to caterpillar development, and its consequences for nestling growth and fledging weight. J Anim Ecol. 1999;68:708-18.

Nicolaus M, Michler SP, Ubels R, Van Der Velde M, Komdeur J, Both C, Tinbergen JM. Sex-specific effects of altered competition on nestling growth and survival: an experimental manipulation of brood size and sex ratio. J Anim Ecol. 2009;78:414-26.

Nilsson JÅ, Gårdmark A. Sibling competition affects individual growth strategies in marsh tit, Parus palustris, nestlings. Anim Behav. 2001;61:357-65.

Nomi D, Yuta T, Koizumi I. Offspring sex ratio of Japanese tits Parus minor is related to laying date and clutch size only in the first clutches. Acta Ornithol. 2015;50:213-20.

O'Brien RM. A caution regarding rules of thumb for variance inflation factors. Qual Quant. 2007:41:673-90.

Oddie KR. Size matters: competition between male and female great tit offspring. J Anim Ecol. 2000;69:903-12.

Poelman EH, Mateman AC, Cassey P. Consistent feeding positions of great tit parents. Anim Behav. 2006;72:1249-57.

Potti J, Dávila JA, Tella JL, Frías Ó, Villar S. Gender and viability selection on morphology in fledgling pied flycatchers. Mol Ecol. 2002;11:1317-26.

Råberg L, Stjernman M, Nilsson JA. Sex and environmental sensitivity in blue tit nestlings. Oecologia. 2005;145:496-503.

R Development Core Team. R: a language and environment for statistical computing. R Foundation for Statistical Computing, Vienna, Austria. 2013. http://www.R-project.org/.
Robinson C, Schumacker RE. Interaction effects: centering, variance inflation factor, and interpretation issues. Mult Linear Regres Viewp. 2009;35:6-11.

Royama T. Factors governing feeding rates, food requirement and brood size of nestling great tits Parus major. Ibis. 1966;108:313-47.

Sandell M, Smith HG. Dominance, prior occupancy, and winter residency in the great tit (Parus major). Behav Ecol Sociobiol. 1991;29:147-52.

Teather KL, Weatherhead PJ. Sex-specific mortality in nestling great-tailed grackles. Ecology. 1989;70:1485-93.

Theofanellis T, Galinou E, Akriotis T. The role of hatching asynchrony in brood size reduction of the great tit Parus major in a Mediterranean pine forest. J Nat Hist. 2008:42:375-80.

Trivers RL, Willard DE. Natural-selection of parental ability to vary sex-ratio of offspring. Science. 1973;179:90-2.

Tschirren B, Fitze PS, Richner H. Sexual dimorphism in susceptibility to parasites and cell-mediated immunity in great tit nestlings. J Anim Ecol. 2003:72:839-45.

Verboven N, Tinbergen JM, Verhulst S. Food, reproductive success and multiple breeding in the Great Tit, Parus major. Ardea. 2001:89:387-406.

Yoshida K. Seasonal population trends of macrolepidopterous larvae on oak trees in Hokkaido, northern Japan. Kontyu. 1985;53:125-33.

Yuta T, Koizumi I. Long breeding season and high frequency of multiple brooding in Great tits in northern Japan. Ardea. 2012;100:197-201.

Yuta T, Koizumi I. Does nest predation risk affect the frequency of extrapair paternity in a socially monogamous passerine? J Avian Biol. 2016:47:153-8.

\section{Submit your next manuscript to BioMed Central and we will help you at every step:}

- We accept pre-submission inquiries

- Our selector tool helps you to find the most relevant journal

- We provide round the clock customer support

- Convenient online submission

- Thorough peer review

- Inclusion in PubMed and all major indexing services

- Maximum visibility for your research

Submit your manuscript at www.biomedcentral.com/submit

(OioMed Central 